\title{
JOGOS EDUCATIVOS COMPUTACIONAIS: UMA INSERÇÃO DE TEMAS AMBIENTAIS PARA O ENSINO FUNDAMENTAL
}

\author{
Herika Bastos de Medeiros ${ }^{1}$
}

\section{Antônio Carlos de Miranda ${ }^{2}$}

RESUMO: Esta pesquisa tem como objetivo abordar questões ambientais, através do Jogo Computacional, e sua relação com os conteúdos da 3a série do Ensino Fundamental Buscam-se estratégias que aliem a esses conteúdos as questões ambientais. Sendo o jogo uma atividade lúdica e motivadora, ele pode ser um instrumento utilizado para servir como base no aprendizado educativo. Nesse sentido, busca-se associar o jogo à educação ambiental de forma interdisciplinar.

Palavras-chave: Jogo computacional, lúdico, educação ambiental

\section{INTRODUÇÃO}

É de fundamental importância motivar e incentivar o interesse para a elaboração de uma proposta pedagógica que contribua para a mudança cultural, respeitando-se as diversidades e a cultura local. Sendo assim, se faz necessário tornar a Educação Ambiental parte integrante dos currículos, incentivando uma nova postura em relação à questão ambiental.

Para Guimarães (2006), o planejamento em EA deve partir da realidade local, mas inserida na realidade global, demonstrando assim, a necessidade de perceber a especificidade de cada meio e a vinculação entre as duas realidades. De acordo com Morin (2010), os fenômenos são cada vez mais fragmentados, e não se consegue conceber a sua unidade, porque as disciplinas se fecham e não se comunicam umas com

\footnotetext{
${ }^{1}$ Mestre em Ensino da Saúde e do Ambiente (UNIPLI), Prof. da Rede Municipal de Itaboraí e São Gonçalo; herikabastos@yahoo.com.br

${ }^{2}$ Doutor (UNICAMP); Prof. do Programa de Pós-Graduação Stricto Sensu - UNIPLI; mirantam@ig.com.br
} 


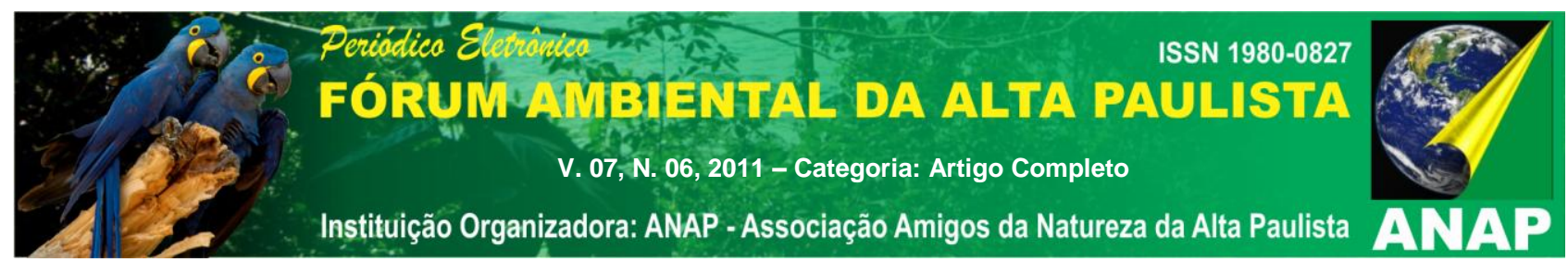

as outras. Essa totalidade é fundamental para compreensão e ação equilibrada no ambiente, que é inteiro e não fragmentado.

"O pensamento complexo não é um conceito manipulável, é o integrar em si próprio uma visão que busca a muldimensionalidade, a contextualização. É uma integração em sua mente de alguns princípios fundamentais. (MORIN, 2004, p. 59)

Nishio e Miranda (2009) frisam que, no ensino da matemática, destacam-se duas abordagens centrais: relacionar, por um lado, observações do mundo real com representações (esquemas, tabelas, figuras); por outro lado, com princípios, estruturas e conceitos matemáticos. Dessa forma, quando interligam temas transversais e meio ambiente, passam a representar um desafio, estabelecendo um vínculo com o mundo real e um ensino que tenha significado para a vida do estudante.

Para Leff (2004), a educação tem como propósito gerar um paradigma oniabrangente de ecologizar o saber ou de formular um método geral para o desenvolvimento do conhecimento, onde o saber ambiental faça com que o aluno venha problematizar o conhecimento sem desmerecer a especificidade das diferentes ciências: historicamente constituídas, ideologicamente legitimadas e socialmente institucionalizadas.

\footnotetext{
"Esse processo de conscientização não deve conscientizar mas modificar as atitudes os novos enfoques e conhecimentos que a interdisciplinaridades exigem, isto é, a cooperação entre as disciplinas tradicionais para aprender a complexidade dos problemas do ambiente e para a formulação de suas soluções" (UNESCO apud Leff 1980: 8-19).
}

Japiassu (2006) nos lembra de que a interdisciplinaridade não é uma categoria do conhecimento, mas de ação e, por isso, "precisa ser entendida como uma atitude" sem ter a ilusão de que basta a simples colocação em contato com os cientistas de diferentes disciplinas para se criar a interdisciplinaridade.

Desde então, educadores são incentivados a promover atividades que apresentam interface com o meio ambiente de forma interdisciplinar, onde o aluno seja o real participante dessa realidade, permitindo assim que ele desenvolva o "pensamento reflexivo e crítico". 


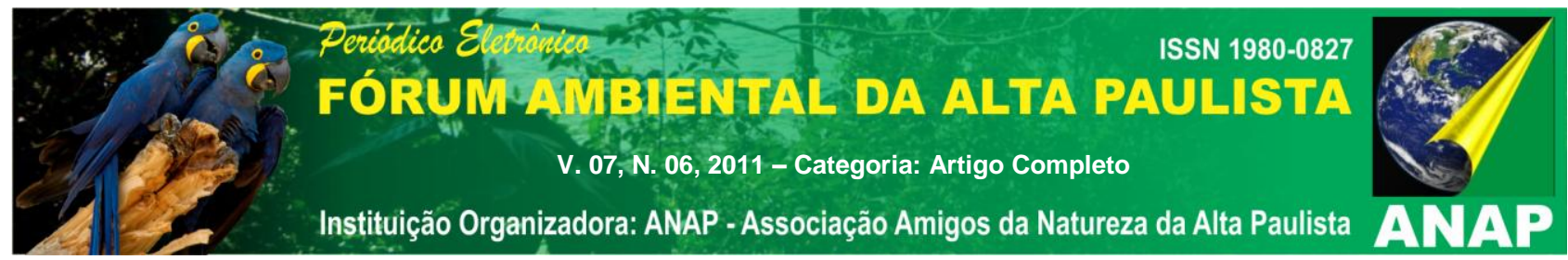

Com o avanço tecnológico, é exigido do profissional da educação que desenvolva novos atributos como: saber trabalhar com o ritmo de cada aluno, apropriar-se das novas tecnologias de elaboração de material didático em ambientes virtuais diferentes e adquirir uma nova linguagem diante da oferta tecnológica. Estudos dessa natureza têm crescido cada vez mais, demonstrando o interesse dos pesquisadores por essa forma de analisar a criança e o jogo no contexto educacional.

Atento a essas questões, esta investigação tem como objetivo geral desenvolver um jogo educativo, de modo que seja um instrumento de ensino-aprendizagem visando explorar conteúdos interdisciplinares associados à educação ambiental.

Por sua vez, tem como objetivos específicos: construir um referencial teórico envolvendo a interdisciplinaridade e o lúdico; identificar artigos que apresentam uma interface com temáticas envolvendo o lúdico, em revistas científicas de educação ambiental; analisar o conteúdo do livro didático adotado pela unidade escolar segundo DCN's e relacioná-lo com uma proposta que envolve a criação e a estrutura de um jogo educacional; planejar e desenvolver ferramentas computacionais adequadas à construção do jogo; registrar e analisar a aplicação do jogo, em sala de aula.

A investigação classifica-se como uma pesquisa qualitativa de caráter exploratóriodescritiva. Enquanto que o seu cenário é a Escola Municipal Presidente Castello Branco, localizada na sede do Município de São Gonçalo, bairro Boaçu. Os sujeitos da pesquisa são dez alunos do $3^{\circ}$ ano do Ensino Fundamental e a sua professora.

\section{DESENVOLVIMENTO}

\subsection{Levantamento em revistas científicas de artigos envolvendo o lúdico em temas ambientais.}

A lei no 9.975/99, que estabelece o Plano Nacional de Educação Ambiental, afirma em seu artigo $2^{\circ}$ que "a educação ambiental é um componente essencial e permanente na educação nacional, devendo estar presente, de forma articulada, em todos os níveis e modalidades do processo educativo, em caráter formal e não-formal”. Para isso, é necessário averiguar quais são os materiais lúdicos voltados para a educação ambiental 


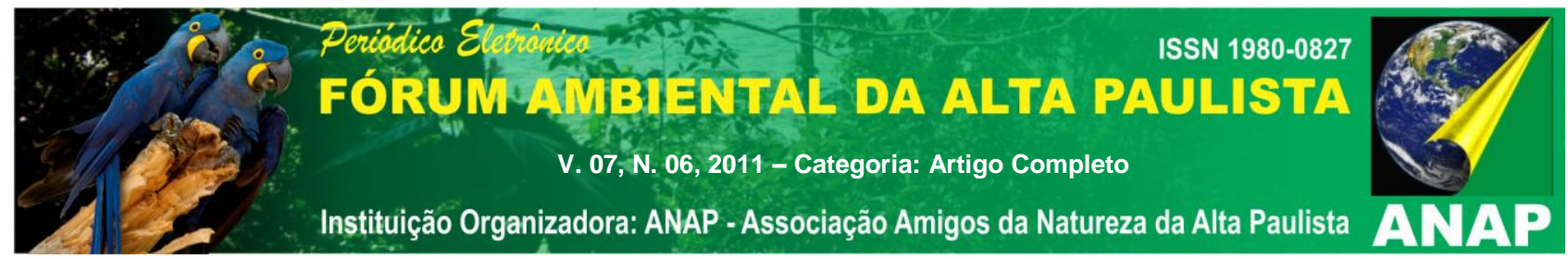

atualmente. A pesquisa foi feita em revistas que abordam o tema educação ambiental e sua interface com o lúdico no processo de ensino-aprendizagem. O levantamento e análise dos artigos científicos têm como orientação dar início ao desenvolvimento do lúdico no ensino da Educação Ambiental. A tabela abaixo mostra as principais revistas eletrônicas pesquisadas entre janeiro de 2008 a dezembro de 2010.

\begin{tabular}{c}
\hline \begin{tabular}{c} 
Revista Ambiental em Ação \\
\hline Revista Eletrônica do Mestrado em Educação Ambiental \\
(REMEA)
\end{tabular} \\
\hline Revista Brasileira de Pesquisa em Educação em Ciências \\
\hline Revista Ambiente \& Educação \\
\hline Revista Ensino, Saúde e Ambiente
\end{tabular}

Tabela 1: Revistas Eletrônicas selecionadas (entre 01/2008 à 12/2010)

Em percentuais, entre os 525 artigos científicos publicados nessas revistas eletrônicas, apenas 1,9 \% abordaram o tema: Lúdico/Educação Ambiental.

Traçado Metodológico: Primeira Etapa

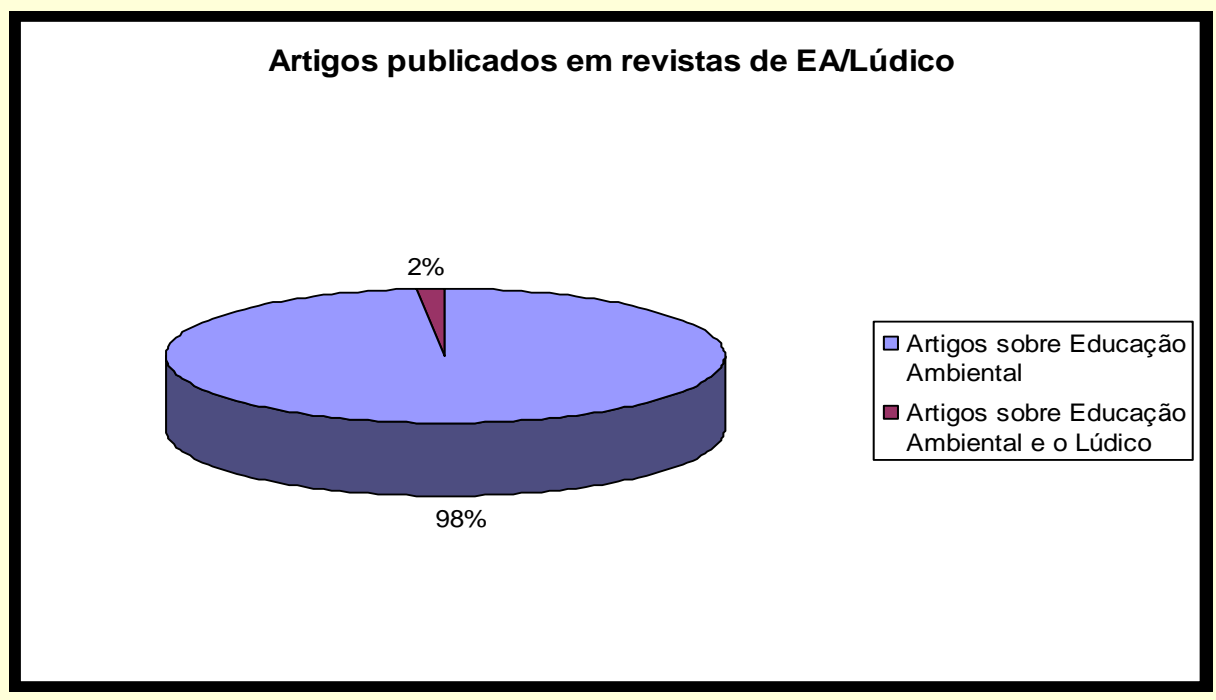

Gráfico 1: Artigos publicados com a temática envolvendo a EA/Lúdico

\subsection{Construção do Jogo}

A construção e o desenvolvimento do jogo foi baseada em conteúdos dos Livros Didáticos adotados na Escola, cenário da pesquisa, e sua aplicação foi feita com os 


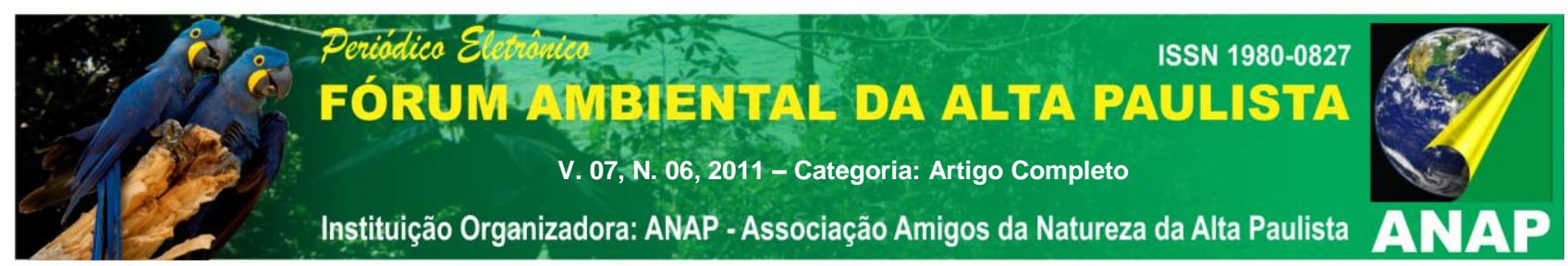

alunos da turma do $3^{\circ}$ ano do ensino fundamental. $O$ universo da pesquisa delimitou-se a dez alunos.

Para produzir os jogos educacionais foi escolhido o Macromedia Flash MX 8.0, um programa utilizado na criação de animações interativas e aplicações, através da linguagem voltada para objetos Actionscript.

O grande sucesso das animações feitas em Flash se deve ao fato de ele utilizar a tecnologia vetorial para construir os objetos e as animações, proporcionando arquivos pequenos, além de ser possível visualizar o carregamento através do navegador, de forma que podemos exibir uma mensagem informando que o site está sendo carregado, enquanto o filme não carrega totalmente. (KNEIPP, MIRANDA e ALBUQUERQUE, 2009, p. 3175)

A interface gráfica do Flash 8.0 permite que mesmo usuários iniciantes possam, de maneira simples, dispor de seus recursos, mesmo sem conhecimentos sólidos de programação.

\subsection{Desenvolvimento do Jogo}

O release inicial foi construído de forma que o aluno possa visualizar na tela principal o jogo e seu respectivo ranking.

Inicialmente, o aluno lerá o release do jogo e identificará a sua temática. Em cada setor que percorrer e avançar, ele terá a resposta correta com a pontuação obtida ou a mensagem "resposta incorreta". As perguntas serão compostas por imagens, onde cada uma delas poderá conter uma ou mais opções corretas. O aluno, após responder todas as perguntas no final do jogo, obterá o total da sua pontuação. Nesse caso, poderá obter entre 0 a 100\% de acertos. Para cada pergunta, existem opções de clicar na(s) opção(s) correta(s), marcar uma única opção, arrastar as partes da figura para compor a imagem ou encaixar objetos nos seus respectivos lugares. Ao clicar na opção errada, aparecerá uma mensagem indicando o erro e a possibilidade de jogar mais uma vez. Ao acertar a questão, surgirá uma mensagem que o encaminhará para a próxima pergunta. Ao término do jogo é emitida a seguinte mensagem: Resultado, Acertos, Erros e Score Total. 


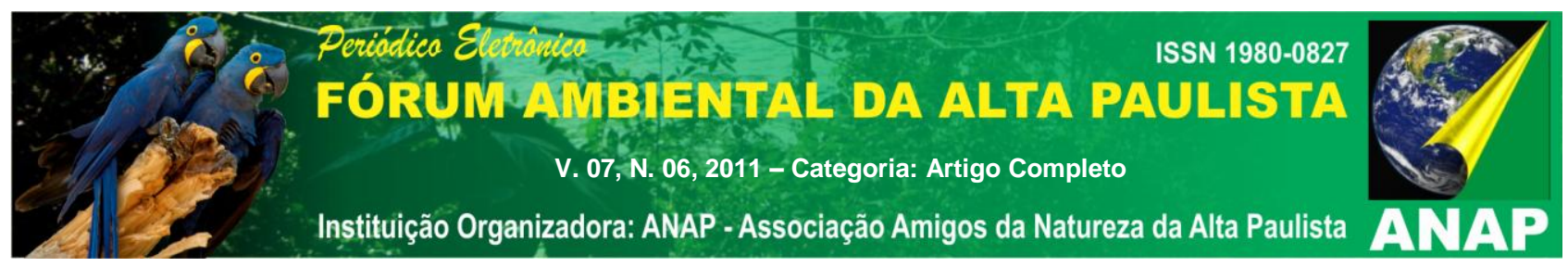

No início do jogo, o aluno será informado que deverá clicar com o mouse no botão "Começar". Esse comando irá iniciar a contagem do tempo que cada aluno utilizará ao responder as respectivas questões e o percentual de acertos. A média do tempo de cada aluno para realizar o Jogo da Geometria foi de aproximadamente 5 minutos e do Jogo do Meio Ambiente foi de aproximadamente 4 minutos e 90 segundos.

No término de cada jogo, o aluno terá acesso ao número de acertos e ao percentual obtido individualmente. Após todos os alunos terem concluído o jogo, o ranking irá demonstrar a pontuação em ordem crescente o percentual de acertos.

\subsection{Etapas do desenvolvimento do Jogo da Geometria e do jogo do Meio Ambiente}

O primeiro jogo é denominado "Jogo da Geometria". Na primeira tela, apresentam-se as informações sobre o conteúdo do jogo. Inicialmente o aluno deverá clicar no botão "começar".

$\mathrm{Na}$ segunda tela, apresenta-se a Igreja Matriz de São Gonçalo "São José do Amarante", solicita-se que o aluno identifique os círculos na figura clicando com o mouse.

$\mathrm{Na}$ terceira tela, apresenta-se a mesma Igreja, mas na figura vê-se 3 linhas verticais (apenas uma delas representa o eixo de simetria da figura) e solicita-se ao aluno que identifique o eixo de simetria clicando com o mouse.

Cabe destacar que a simetria é uma característica que pode ser observadas nas várias vertentes da ação humana: na geometria, matemática, física, biologia, arquitetura, na literatura, na arte, entre outras.

$\mathrm{Na}$ quarta tela, solicita-se ao aluno que identifique os triângulos na parte frontal da Igreja clicando com o mouse.

Como já citado anteriormente pelo DCN's as noções geométricas que favorecem o aluno a desenvolver a compreensão do mundo em que vive. Estabelecendo conexões entre Matemática e outras áreas. 

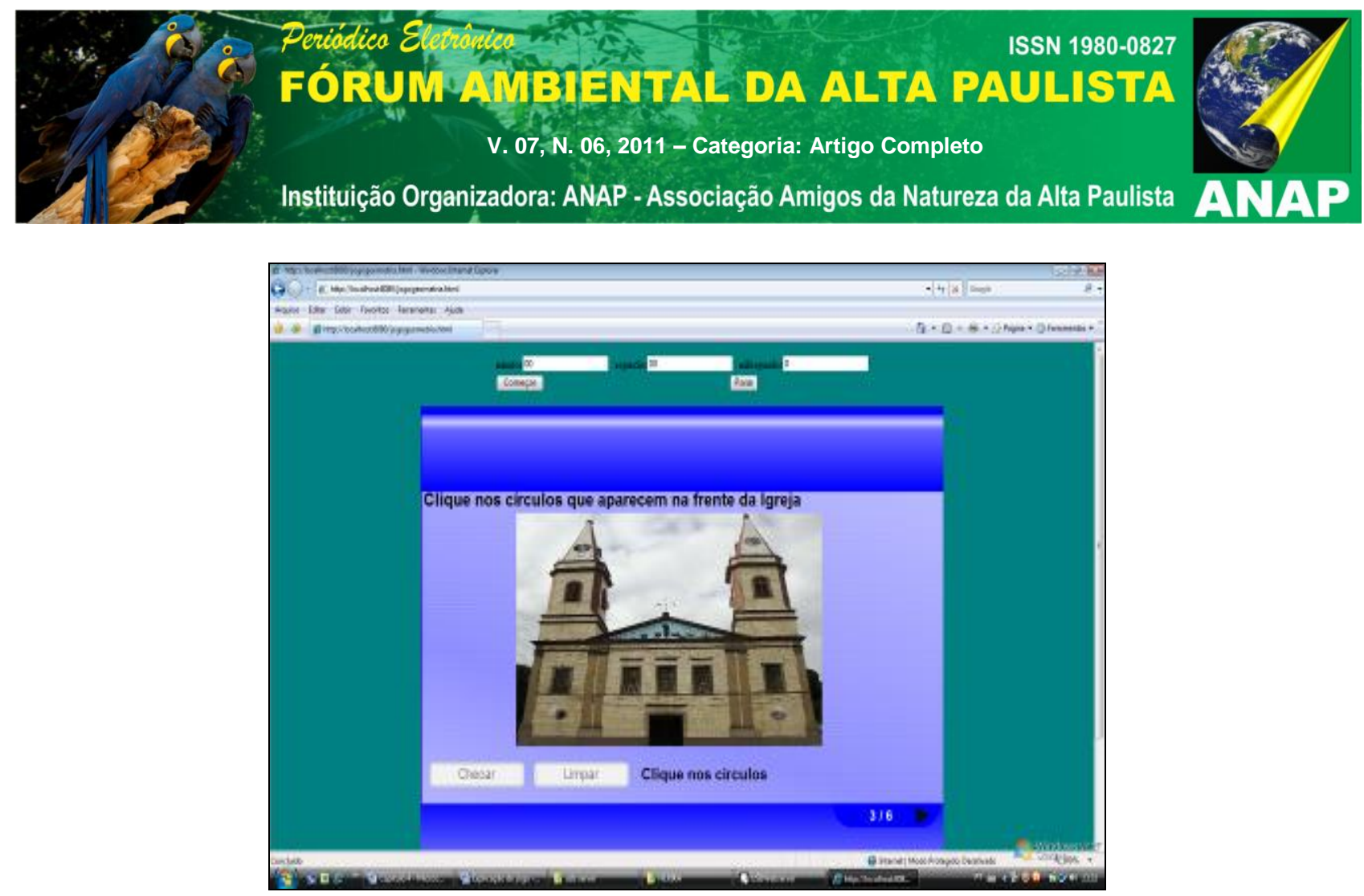

Figura 1: Tela do Jogo da Geometria

No “Jogo do Meio Ambiente", na primeira tela, apresentam-se as informações sobre o conteúdo do jogo. É nesta tela que o aluno deverá clicar no botão "começar".

$\mathrm{Na}$ segunda tela, solicita-se ao aluno que arraste os diferentes objetos para a lixeira correspondente.

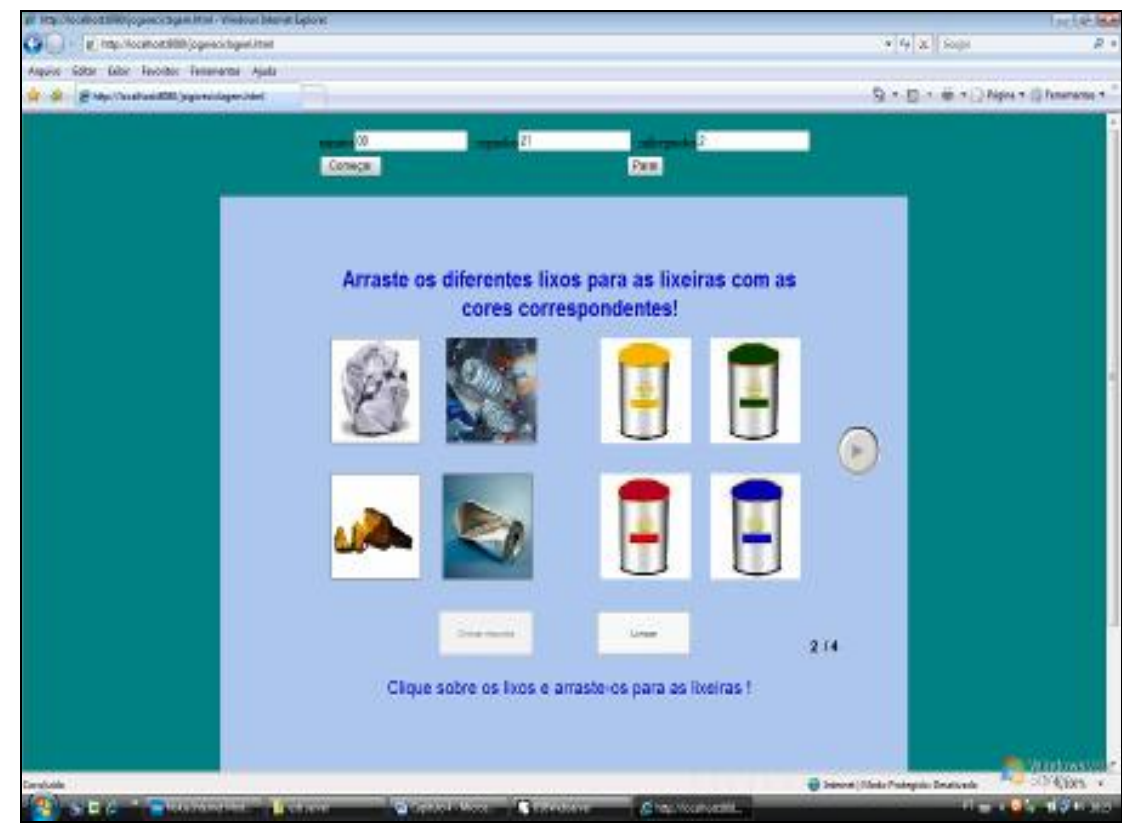

Figura 2: Segunda Tela do Jogo do Meio Ambiente

Na terceira tela, solicita-se que o aluno arraste com o mouse para a caçamba de lixo os três objetos que estão poluindo a paisagem. Quando o aluno terminar a quarta 


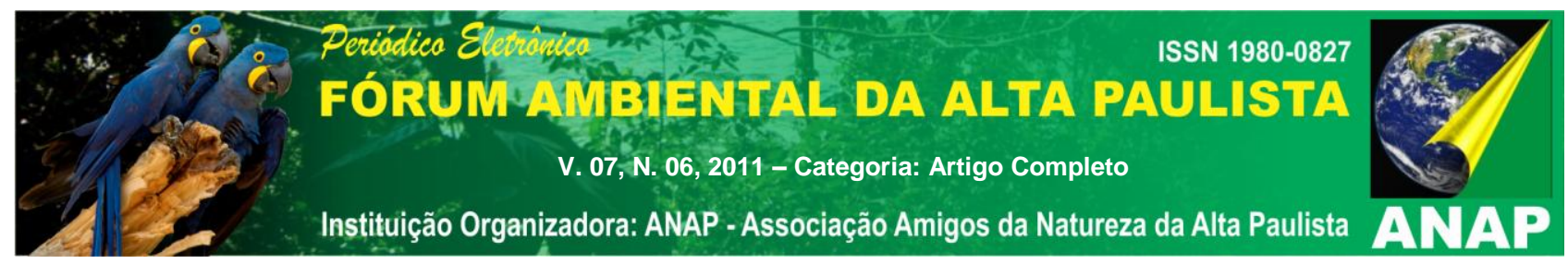

tela, deverá clicar com o mouse no botão "parar". Nesse momento, ele saberá que é a última tela do jogo porque aparecerá o item 4/4 na parte inferior do release

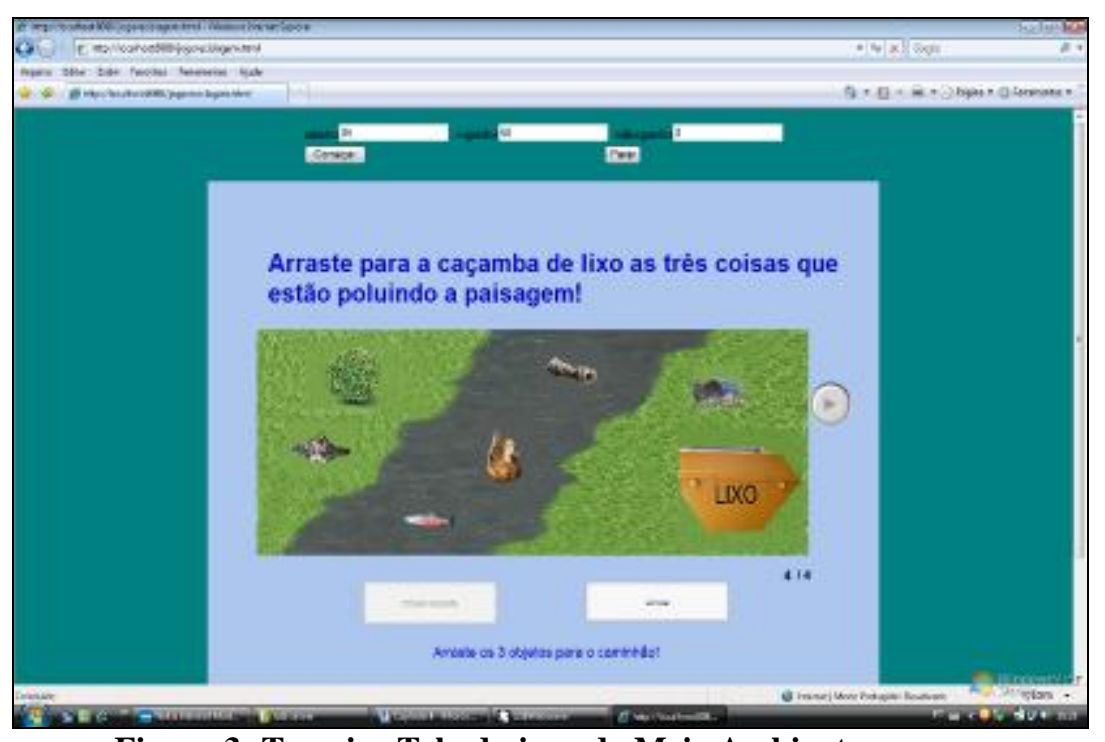

Figura 3: Terceira Tela do jogo do Meio Ambiente

Conforme citado por Miranda, Gomes e Silva (2006), o crescente desenvolvimento urbano acelera esse processo, pois são geradas quantidades de resíduos tóxicos originados de produtos que fazem parte do uso no dia-a-dia, tais como pilhas, lâmpadas, produtos de limpeza em geral, inseticidas entre outros, que vão ter como destino os lixões.

\subsection{Registro e Análise das características observadas durante o jogo}

Os sujeitos desta pesquisa são alunos de uma turma do $3^{\circ}$ ano do primeiro segmento do ensino fundamental e também a sua professora, da Escola Municipal Presidente Castello Branco.

Antes de dar início a aplicação do Jogo, fez-se uma análise dos conteúdos no livro didático adotado pela Unidade Escolar, do PPP (Projeto Político Pedagógico) e do Plano de Curso, em relação aos temas propostos.

Cabe destacar que o PPP da Unidade Escolar foi estabelecido em 2010 e anualmente é feito ajuste mediante necessidade. O PPP é um instrumento 


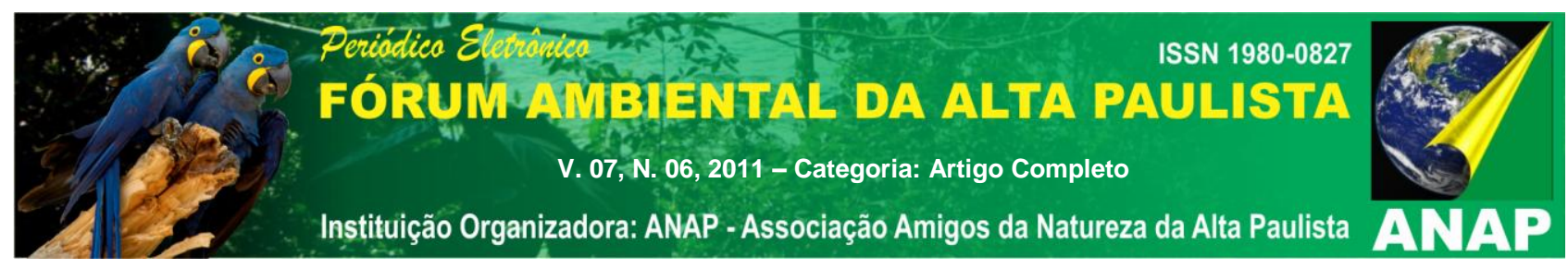

organiza ações, dá voz aos atores educacionais, otimiza recursos financeiros, facilita a continuidade administrativa, mobiliza diferentes setores na busca de objetos comuns, e por ser domínio público, permite constante acompanhamento e avaliação (Silva apud Cleonice, 2009: 90)

Inicialmente, durante os encontros pedagógicos, identificamos os conteúdos programáticos do $3^{\circ}$ ano que poderiam ser explorados em visita aos pontos turísticos de São Gonçalo, como a Igreja São José do Amarante, apresentada no Jogo da Geometria, tendo como referência o livro didático, o PPP (Projeto Político Pedagógico) e as Diretrizes Curriculares Nacionais.

Em uma primeira etapa, os alunos responderam algumas questões, relativas ao uso do computador. Na $1^{\text {a }}$ questão, (Você já tinha utilizado o computador antes?), todos os alunos responderam que sim, e observamos que o fato da escola possuir um laboratório de informática facilitou o acesso dos alunos ao computador.

"eu já fui na sala de informática uma vez com o professor, mas tem computador na casa dos meus primos". (relato do aluno A).

Juca (2006) destaca que o conhecimento dos princípios básicos de informática torna-se indispensável à formação da cidadania contemporânea. Por isso, é necessário que o ensino possa fornecer um conjunto de competências específicas que permitam perceber e interagir com a evolução tecnológica presente no cotidiano.

Em resposta à $2^{\mathrm{a}}$ questão, (Você tem computador em casa?), $80 \%$ dos alunos responderam afirmativamente, porém os que não possuem utilizam na casa de algum parente, vizinho ou na própria escola. 

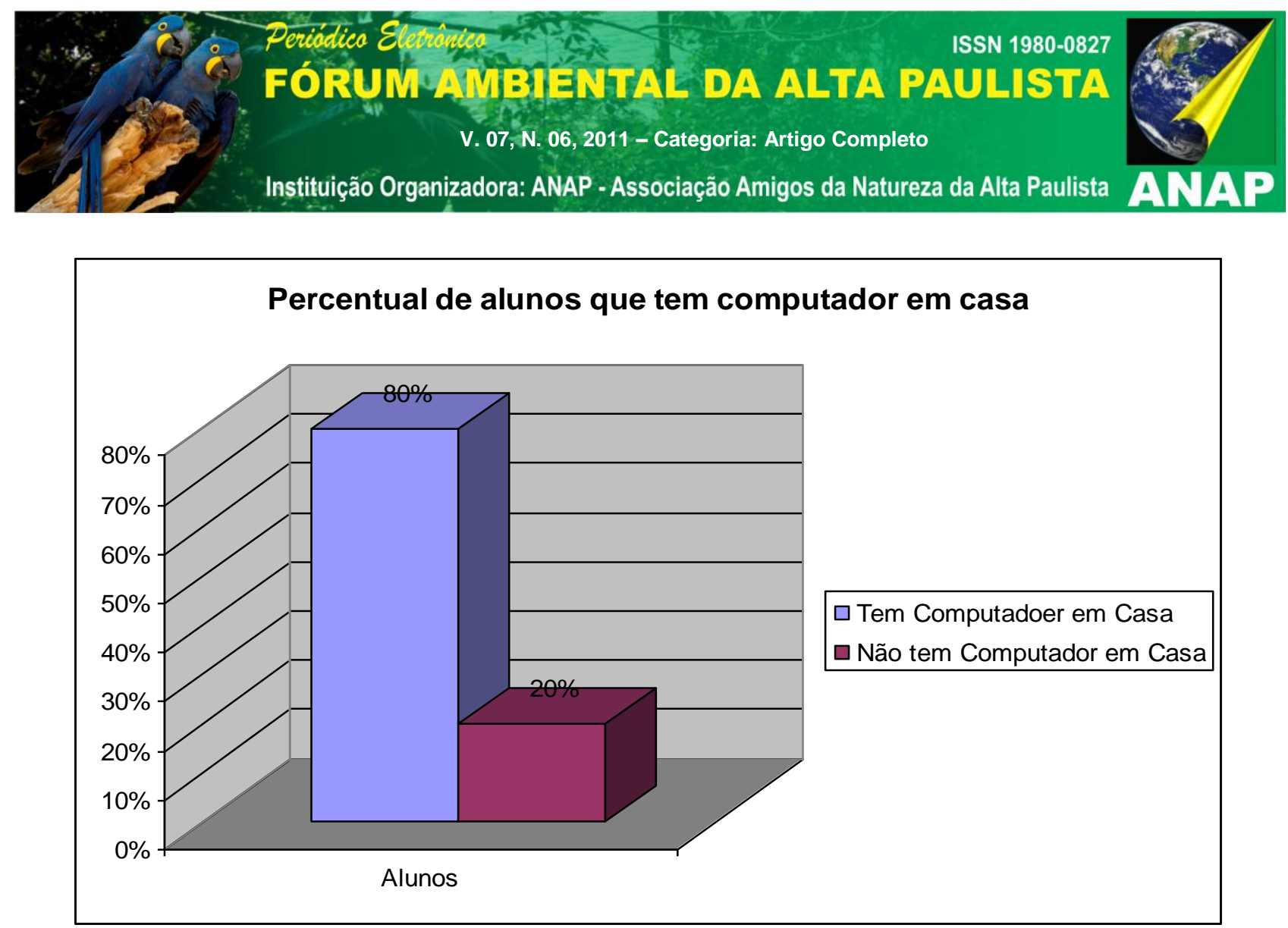

Gráfico 2- Percentual de alunos que têm computador em casa

$\mathrm{Na} 3^{\text {a }}$ questão, (Onde você utiliza mais o computador?), todos têm acesso ao computador e utilizam com maior frequência 50\%, na Lan House, 30\% na escola e $20 \%$ em casa. Observa-se que a maioria não apresenta dificuldades quanto ao manuseio do computador e temos os seguintes relatos:

"aqui na escola vamos poucas vezes ao laboratório de informática, porque não tem professor para levar a gente. Eu uso computador em casa e às vezes vou a Lan house, para acessar a internet". (aluno C).

"a sala de informática tem ficado fechada e a tia às vezes marca para levar a turma e no dia não pode ir porque não tem ninguém lá". (aluno J).

"eu uso computador em casa, mas não tem internet. Na casa do meu primo tem computador com internet, e quando eu quero fazer alguma pesquisa ou jogar vou para casa dele ou para uma loja que tem internet, que fica perto da minha casa." (aluno D)

A maioria dos alunos diz que foram poucas vezes ao laboratório de informática e que aprenderam a utilizar o computador com o auxílio de um colega, alguém da família ou na Lan house. 


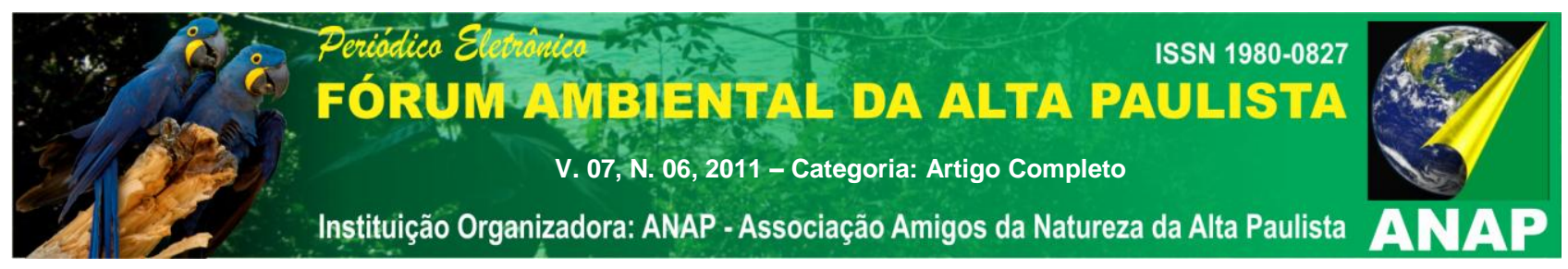

O pouco contato e estímulo por parte dos profissionais da educação para com a área tecnológica vêm contribuir para que não se tenha uma possibilidade de avaliação satisfatória dos softwares utilizados na educação.

O computador, símbolo e principal instrumento do avanço tecnológico, não pode ser ignorado pela escola. O desafio é colocar todo o potencial dessa tecnologia a serviço do aperfeiçoamento do processo educacional, aliandoa ao projeto da escola com o objetivo de preparar o futuro cidadão. (Milani apud Gomes, 2002).

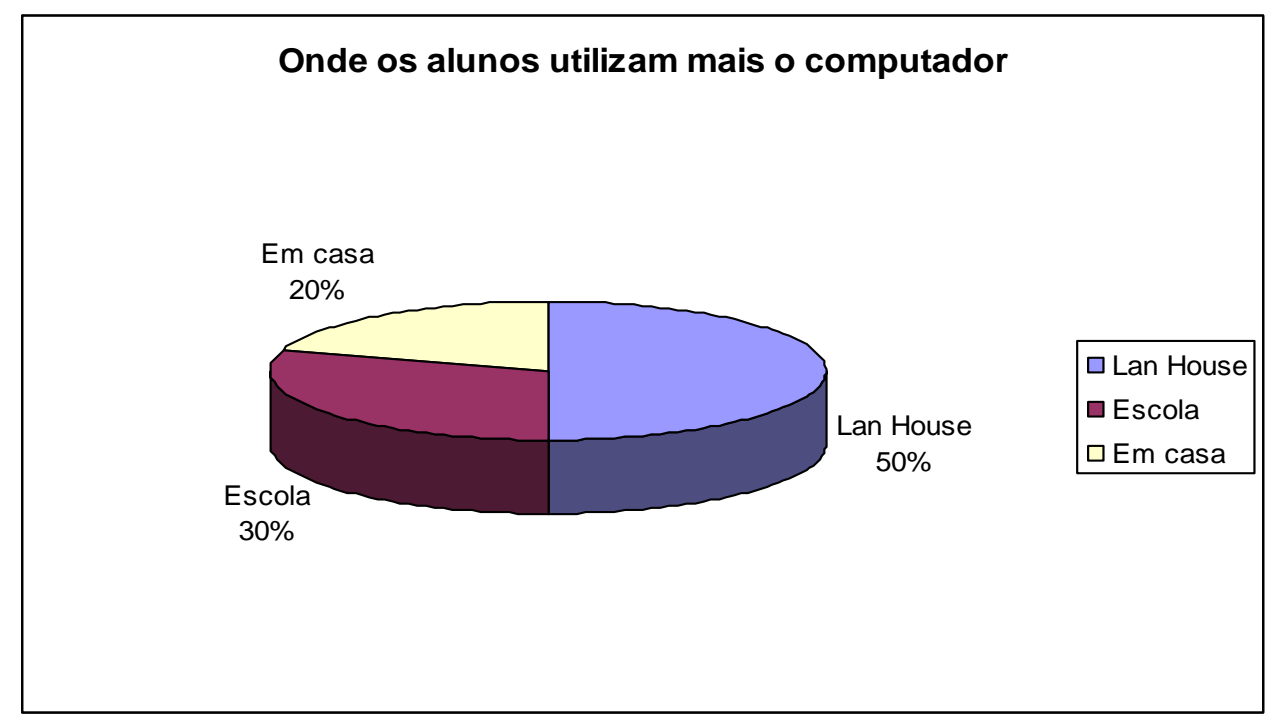

Gráfico 3-Local onde os alunos utilizam mais o computador

Na quarta questão, (Que jogo achou mais fácil?), os alunos indicaram o "Jogo da Geometria" com 70\% dos votos, o "Jogo do Meio Ambiente" com 20\%, enquanto 10\% relataram que ambos estavam fáceis de jogar. 

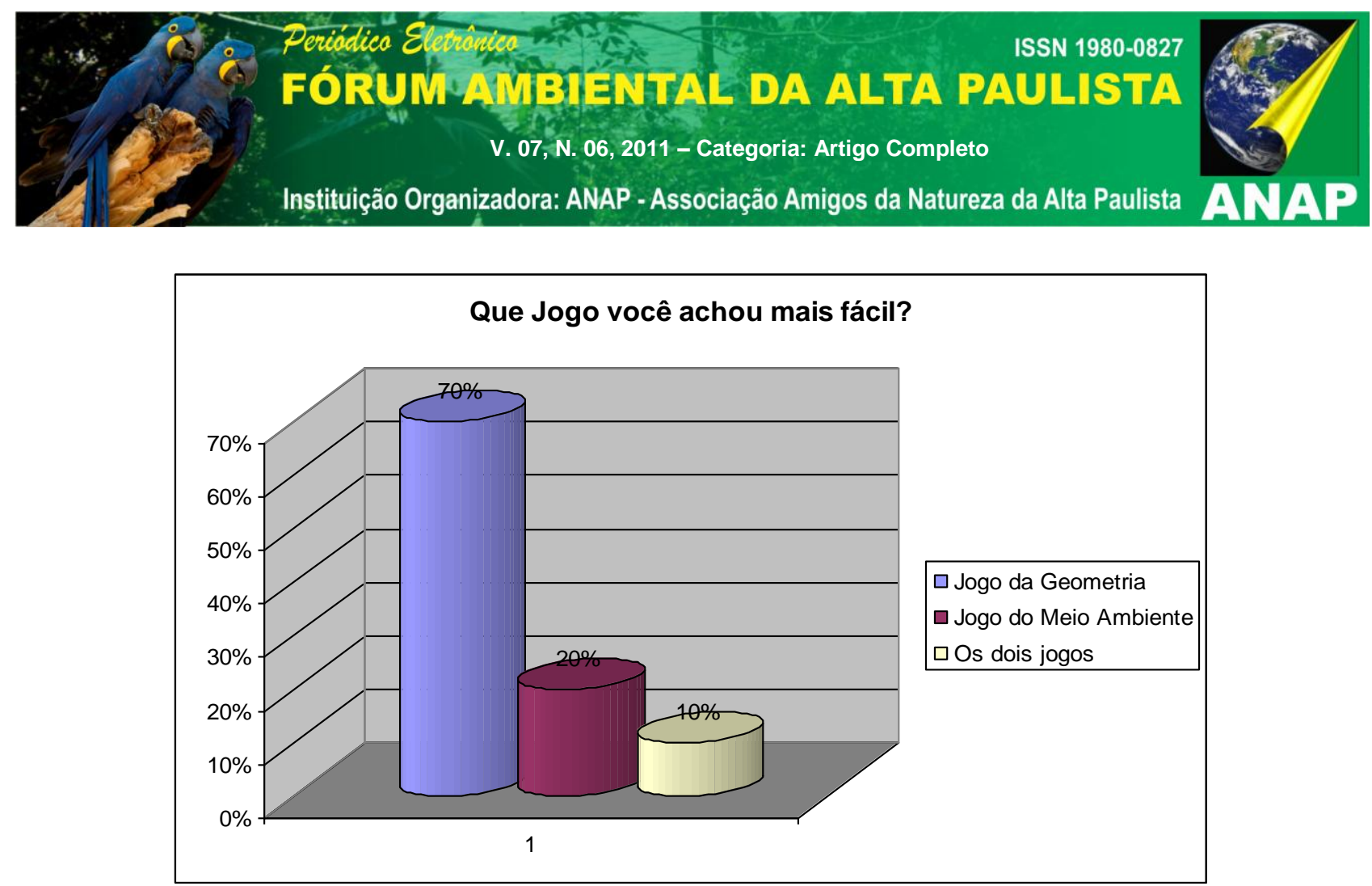

Gráfico 4- Que Jogo você achou mais fácil?

Esses dados, segundo a professora, indicam que:

"Eles teriam mais facilidade no jogo do Meio Ambiente pelo fato de que as imagens e/ou conteúdos contidos terem sido apresentados no livro adotado pela escola. Já no Jogo da Geometria, as figuras geométricas foram também trabalhadas no livro didático e comparadas com imagens pesquisadas pelos próprios alunos. Porém, achei que fossem ter dificuldades em identificá-las na imagem da Igreja Matriz de São Gonçalo".

Foi perguntado ao aluno que parte no "Jogo da Geometria" ou do "Jogo do Meio Ambiente" que você teve maior dificuldade? Os alguns alunos fizeram o seguinte comentário:

\author{
Aluno A disse: "Cadê o nome no lixo?" \\ Aluno B disse: "A tia deu isso, mas não lembro" \\ Aluno J disse: "Não tem como ler no lixo!"
}

No release 3/5 do Jogo da Geometria, no qual o aluno é orientado a identificar com os três triângulos localizados na parte frontal da Igreja, fizeram as seguintes observações:

Aluno C: "Essa figura mais larga é um triângulo?"

Aluno D: "Este triângulo não é igual ao outro?"

Aluno E: "Tem mais outro triângulo além desses dois"? 


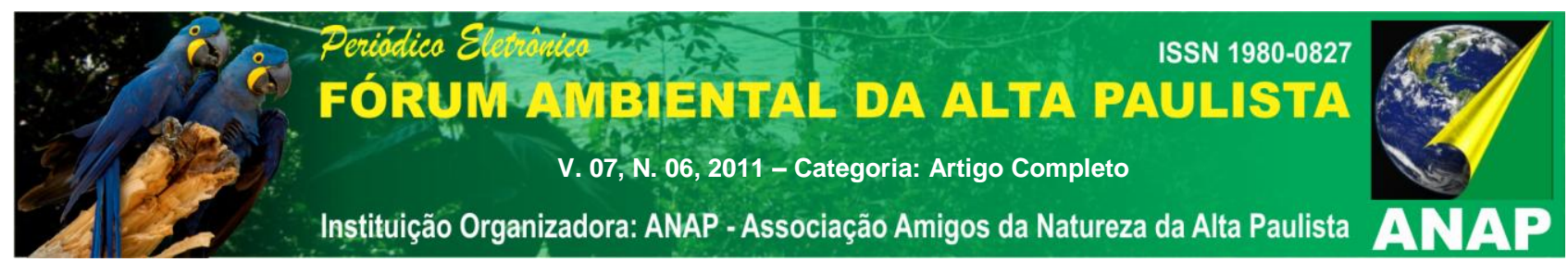

Um aspecto que apresentou dificuldade para os alunos foi o fato de não ter acrescentado no release 2/4 do "Jogo do Meio Ambiente" o nome do tipo de resíduos no depósito do lixo. Na escola eles aprendem a associar o nome às suas respectivas cores, no entanto, no jogo eles apresentaram dificuldade. Esses dados permitem sugerir que seria interessante reforçar essa temática, que envolve a distribuição dos resíduos sólidos em suas respectivas lixeiras, a fim de que possam assimilar não apenas o nome da casa e tipo de resíduo, mas também as suas respectivas cores.

Em relação ao jogo da geometria, cabe lembrar Padovan, Guerra e Milan (2008), quando afirmam que a simetria não só está presente em figuras geométricas e objetos construídos pelo ser humano, mas também em elementos da natureza. Já Bangs (2010), questiona o porquê destaca que os estudos da proporção, da harmonia e da forma são frequentemente ignorados nas escolas.

Por sua vez, a professora diz que ficou surpresa ao perceber a desenvoltura dos alunos durante os jogos e os resultados obtidos. Afirma, ainda, que percebeu que os "jogos" estão relacionados ao conteúdo programático trabalhado durante as aulas.

\begin{abstract}
“No 'Jogo da Geometria' é apresentada a imagem da Igreja Matriz de São Gonçalo e solicitado ao aluno que identifique as formas geométricas como: círculo, triângulo e retângulo, teve associação do conteúdo de história, no qual os alunos estudaram características do nosso município com o conteúdo de matemática.

No 'Jogo do Meio Ambiente' são apresentados diversos assuntos relacionados com o livro didático como: a parte de arrastar o lixo para a lixeira correspondente é trabalhada no livro de Português, em 'Cuidando do Meio Ambiente' e no livro de Matemática, em 'Motivos para separar o lixo'. Acho que os alunos apresentaram um pouco de dificuldade no momento que eles não viram o nome nas respectivas lixeiras. Também achei interessante na parte que aparece a imagem de um rio onde são encontrados objetos que poluem, no livro de ciências é apresentado a imagem de um rio, com casas próximas e coisas que compunham o rio."
\end{abstract}

De acordo com Alves e Figueiró (2010) a educação ambiental deve ser trabalhada pelo conjunto de disciplinas que estão inseridas no currículo. Este princípio, de uma EA como prática educativa integrada, está contido nas diretrizes da Política Nacional de $\mathrm{EA}^{3}$, devendo ser desenvolvida de forma contínua e permanente.

\footnotetext{
${ }^{3}$ Lei 9.795 , de 27 de abril de 1999 , art. $10^{\circ}$.
} 


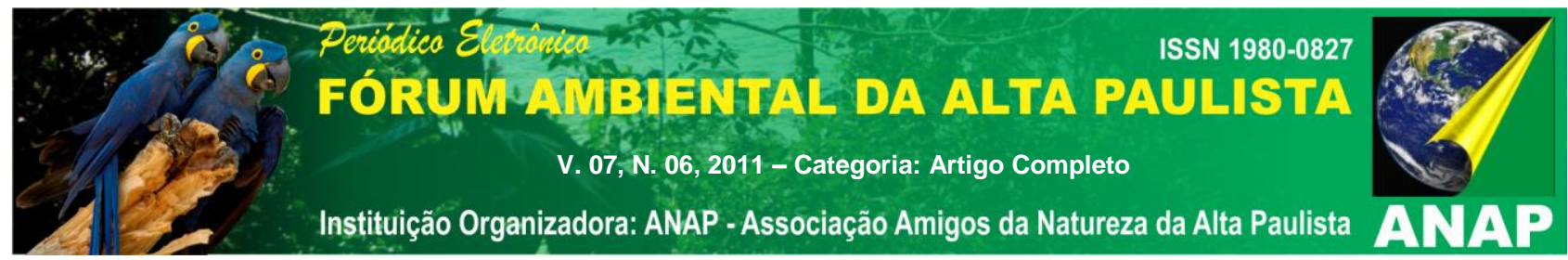

Vygotsky (1984) comenta que "a cultura forma a inteligência e a brincadeira favorece a criação de situações imaginárias e reorganiza experiências vividas". Por outro lado, segundo (Juca apud Freire, 2006), o aluno deve ser capaz de participar desse mundo que cada vez mais se compõe de ambientes informatizados.

Segundo David (2002), a participação da criança na mídia, especialmente da internet, deve ser vista como extremamente positiva para os jovens em busca de autodesenvolvimento, autonomia progressiva e de interação completa. Por sua vez, Kishimoto (2002) afirma que a utilização do jogo potencializa a exploração e a construção do conhecimento por contar com a motivação interna típica do lúdico. Segundo (Vygotsky apud Kneipp, 1984), o brincar tem sua origem na situação imaginada que foi criada pela criança, que, ao realizar seus desejos, reduz as tensões e constitui uma maneira de acomodação e conflitos e frustrações. O mais importante não é a similaridade do objeto com a coisa imaginada, mas o gesto, tornando seu significado mais importante que o próprio objeto. Assim, a grande importância do jogo no desenvolvimento deve-se ao fato de criar novas relações entre situações dos pensamentos e situações reais. Desse jeito, Rebeca (2010) diz "que o ato de brincar é o caminho natural do desenvolvimento humano".

\section{CONCLUSÃO}

Inicialmente, através de vários autores, como, por exemplo, Vygotsky, Huizinga, Kishimoto, entre outros, foi possível perceber a importância dos jogos no processo ensino-aprendizagem. Por outro lado, através do levantamento realizado em revista de Educação Ambiental, constatou-se também que são poucas as propostas (artigos publicados) que utilizam o Lúdico associado a sua potencialidade no desenvolvimento cognitivo. Nesse sentido, justifica-se a importância dessa investigação pela necessidade de uma proposta integrando o lúdico e a Educação Ambiental voltada para o ensino fundamental. Percebemos que os jogos representam uma importante estratégia de ensino-aprendizagem. Acreditamos que, com a utilização do lúdico, aplicado em software educativo, foi possível elaborar situações que envolvessem os Temas Transversais 


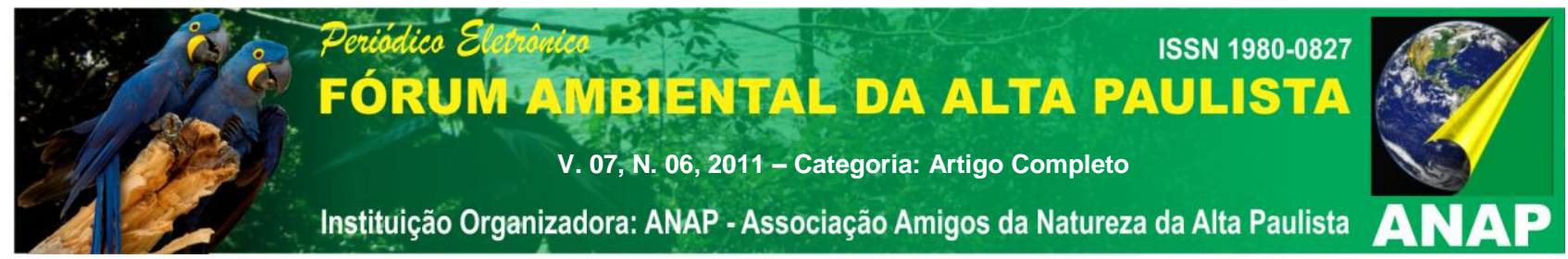

atrelados ao conteúdo programático, visando à abordagem de questões relativas à Educação Ambiental em sala de aula. Além disso, estabeleceram-se significados com as questões do município em que os alunos vivem. Por outro lado, acreditamos que, em conjunto com a construção de atividades lúdicas, deve-se buscar também a implantação de Educação Ambiental no Projeto Político Pedagógico, elaborando ações pedagógicas que perpassem pelas disciplinas, conforme orientações da Lei 9795/99, com suas recomendações para auxiliar os docentes na compreensão da transversalidade de EA. Além disso, devem-se elaborar novas pautas nas reuniões pedagógicas com o corpo docente, com objetivos de ampliar conhecimentos de EA, romper com a visão tradicional e motivando o docente a ser um articulador do aprendizado, construindo novos olhares em novas relações entre homem, sociedade e natureza, através de uma proposta crítica reflexiva e contínua em Educação Ambiental.

\section{REFERÊNCIAS}

ALVES, Daniel Borini; FIGUEIRO, Adriano Severo. A. S. O lúdico na cartografia dos conflitos socioambientais no bairro Itararé: $O$ jogo como instrumento de construção de cidadania. Revista Eletrônica do Mestrado em Educação Ambiental, v. 24, jan/jul, 2010.

Apostila Macromedia Flash- Avançado com Actionscript. Disponível em <http: //www.baixaaqui.com.br>, acessado em 20 de março de 2011.

BANGS, Herbert. O Retorno da Arquitetura Sagrada: a razão Áurea e o Fim do Modernismo. São Paulo: Editora Pensamento, 2010.

BRASIL, Ministério da Educação. Coordenação Geral de Educação Ambiental: Ministério do Meio Ambiente. Vamos cuidar do Brasil: conceitos e práticas em educação ambiental na escola. In. Mauro Guimarães. Educação Ambiental: além dos muros da escola: UNESCO, 2007.

DAVID, Paulo. Os Direitos da Criança e a Mídia: Conciliando proteção e participação. In: ULLA, Carlsson e FEILITZEN, Cecília Von. A criança e a Mídia. Imagem, Educação, Participação. São Paulo: Editora Cortez, p. 37-41. 2002.

HUIZINGA. Johan. Homo Ludens: O Jogo como Elemento da cultura. São Paulo, Perspectiva, 2001.

JAPIASSU, Hilton. O sonho transdisciplinar e as razões da filosofia. Rio de Janeiro: Imago, 2006. 


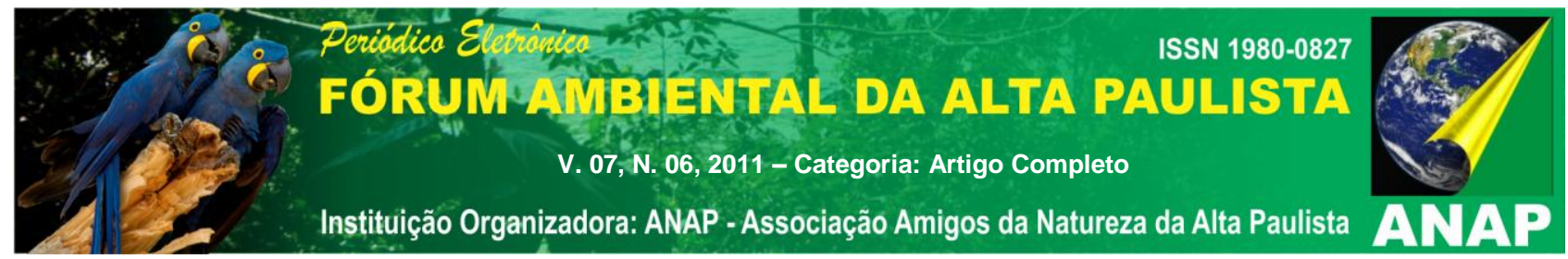

KISHIMOTO, Tizuko Morchida. Jogos Infantis: o Jogo a Criança e a Educação. 10ª edição. Petrópolis: Vozes, 1993

LEFF, Henrique. Saber Ambiental. Sustentabilidade, Racionalidade, complexidade e poder. Editora Vozes, São Paulo, 2004.

KNEIPP, Ricardo; MIRANDA, Antonio Carlos de; ALBUQUERQUE, Rodney. Jogos na web: instrumento de ensino-aprendizagem de educação ambiental no ensino fundamental. Revista Iberoamericana de Educación. Número 38/2, 2006.

MIRANDA, Antonio Carlos de; GOMES, Haroldo Pereira; SILVA, Márcia Oliveira da. Recursos Hídricos: A Gestão das águas, a Preservação da Vida. Rio de Janeiro: Editora All Print, 2006.

MORIN, Edgar. Ciência com consciência. 13ª edição. Rio de Janeiro: Bertrand, 2010.

MORIN, Edgar. Saberes Globais e Saberes Locais o olhar transdisciplinar, Rio de Janeiro: Garamond, 2004.

NISHIO, Ana; Miranda, Antonio Carlos. Matemática e meio ambiente: uma proposta interdisciplinar. Enseñanza de las ciências, v. viii, p. 3174 - 3178, 2009.

PADOVAN, Daniela; GUERRA, Isabel Cristina; MILAN, Ivonildes. Matemática. Projeto Prosa. Ensino Fundamental- 3ํano. Editora Saraiva, São Paulo, 2008.

VIGOTSKY, Lev. S. Linguagem, desenvolvimento e aprendizagem. São Paulo: Ícone, 1988.

Pensamento e linguagem. São Paulo: Martins Fontes, 1998.

A formação social da mente: o desenvolvimento dos processos psicológicos superiores. São Paulo: Editora Martins.

ZEBA, Clenĺcia. Acesso do professor à educação continuada em Educação Ambiental: à luz da lei 9795/99. Niterói, UNIPLI, 2009. (Dissertação de Mestrado em Mestrado Profissionalizante em Ensino de Ciências da Saúde e do Ambiente). 